\title{
Cuba-Guatemala Cooperation: Building Viable Models for Health
}

\section{By Conner Gorry, MA}

The intertwined history of Cuba and Guatemala goes back almost five centuries. In 1536, Friar Bartolomé de las Casas sailed from Cuba to Guatemala with material for his book, A Brief Account of the Destruction of the Indies, seared upon his conscience. Documenting atrocities against Cuba's indigenous populations, the book persuaded Guatemala's colonial powers to rewrite abusive labor laws that were killing the Maya; the book also earned De las Casas the nickname 'apostle of the Indians.' Over 300 years later, the apostle of Cuban independence, José Martí, cut his journalistic teeth in Guatemala, while Cuban poet José Joaquín Palma authored Guatemala's national anthem. More recently, in the 1950s, Dr Ernesto ('Che') Guevara's time in the country solidified his belief in the need for radical social change a few years before he would join Fidel Castro's Rebel Army.

And in 1998, Guatemala, like Cuba so many times before and since, was struck by a fierce, fatal hurricane, opening in its wake a new chapter in the countries' shared history. Hurricane Mitch took over 30,000 lives in Central America and is widely considered the deadliest hurricane to hit the Western Hemisphere in 200 years. The storm made landfall in Guatemala on October 26, 1998 killing 268 people and displacing 106,000. Losses were estimated at US $\$ 750$ million, with 6,000 homes completely destroyed and another 20,000 damaged. Seven health centers and 48 rural health stations serving 50,000 people were affected.[1] Within days, a team of 19 Cuban doctors landed in Puerto San José in the southern department of Escuintla to provide medical assistance. Working alongside Spanish, US, and Guatemalan relief workers, the Cuban contingent set broken bones, treated some 900 cases of cholera[2] and 14,000 of malaria,[3] evacuated pregnant women, and delivered babies. Implementing vector control, safeguarding food supplies, and providing potable water were other measures taken by the Cuban volunteers, who drew on their own experiences in hurricane recovery.

But the disaster wrought by Mitch was unlike anything these professionals had seen in Cuba-not because of the hurricane's strength, but because of the Guatemalans' generally poor state of health and lack of accessible health care, adequate nutrition, clean water, and decent housing before the storm. While righting systemic social determinants that put Guatemala's poor majority at such risk was beyond the scope of the medical team's disaster aid, this first-hand experience inspired major innovations in $\mathrm{Cu}$ ban international health cooperation.

As a result, Cuba's Comprehensive Health Program (CHP) was launched in late 1998 to generate sustainable models for posting health professionals in remote and underserved areas to improve population health in dozens of countries, beginning with Central America. The idea was to send Cuban doctors, nurses, and technicians for long-term service, eventually to be replaced by local professionals trained in Cuba. Key to the program was establishment of the Latin American Medical School (abbreviated in Spanish as ELAM), which opened its doors in early 1999 to scholarship students from low-income families from the region. Today, there are 37 countries hosting CHP medical teams and students from 30 countries enrolled at ELAM.[4] In both cases, Guatemala was one of the first countries to participate.

Guatemala Departments with Cuban Medical Cooperation (17 of 22)

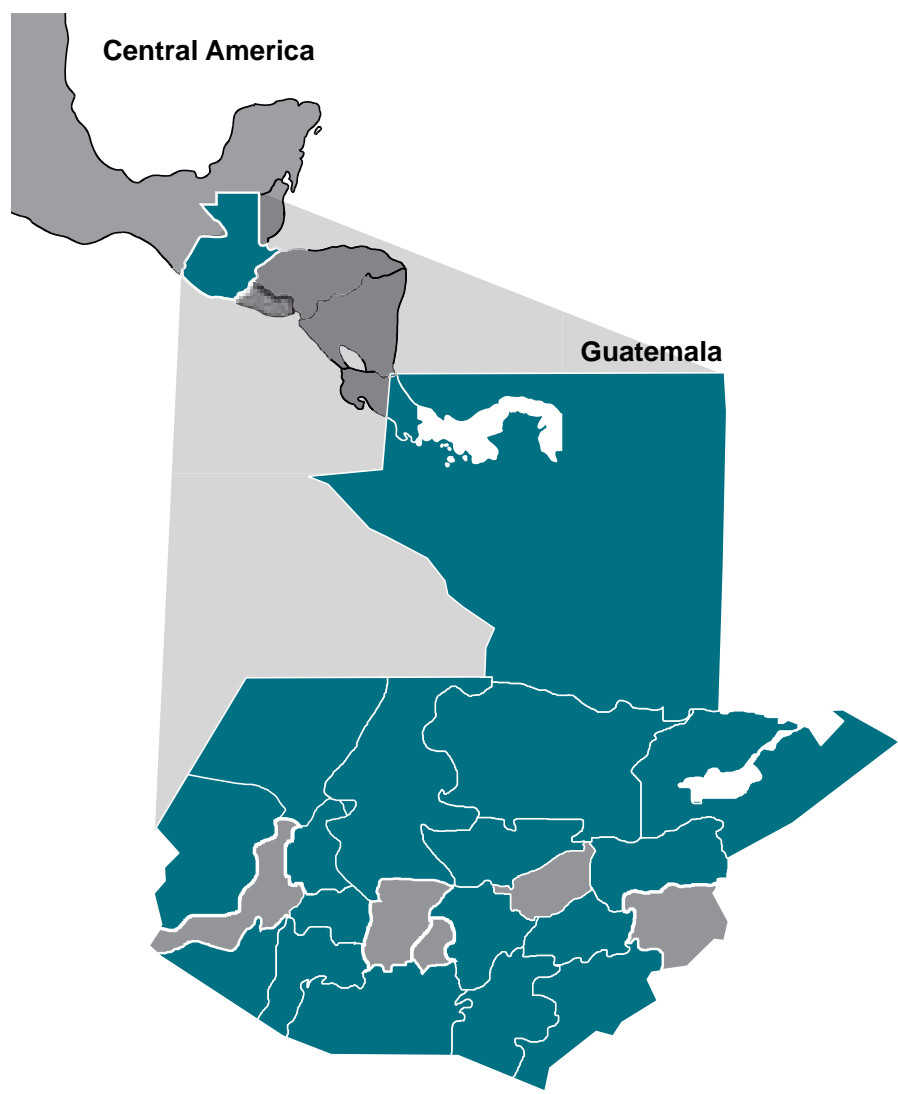

Source: Cuban Medical Team, Guatemala 2008, PowerPoint presentation.

\section{"Coca-Cola \& Cuban Doctors"}

The philosophy behind the Comprehensive Health Program is simple: by living and working in underserved communitiesincluding the most remote-Cuban doctors bolster local public health systems to improve population health. However, putting theory into practice in Guatemala is not so simple, beginning with the country's stark geographical contrasts, which include Central America's highest peaks and the largest tract of virgin rainforest north of the Amazon. The high altitudes, cold air, changeable climate, and inadequate, overcrowded housing make acute respiratory infections the number one cause of death in children under age one.[3] At the opposite extreme, the hot, steamy lowlands are breeding grounds for dengue, malaria, cholera, and snakes (snake bites are among the injuries most frequently seen by Cuban doctors working in the jungle-bound department of Petén).

For many Guatemalans, the extensive mountain ranges and river systems, lakes, and nearly impenetrable jungle combine with poor roads and scarce transportation to make health centers and 


\section{International Cooperation Report}

hospitals extraordinarily difficult to access. One of the tenets of Cuba's international cooperation addresses such issues of access: Cuban volunteer doctors live in the remote communities they serve, bringing health care directly to residents. In Guatemala's farthest flung regions, however, this still means traveling up to eight hours on foot or taking three buses and a boat to get to some patients. Thus, it's not surprising that the first doctor some villagers have ever seen is a Cuban. In fact, there's a saying in Guatemala that "there are only two things that make it to the most remote parts of the country: Coca-Cola and Cuban doctors."[5]

But beyond geographical barriers to health are still tougher cultural challenges. Some $60 \%$ of Guatemala's population is indigenous,[6] and while this largely Maya citizenry shares common traditions and history, 24 different languages are spoken around the country. Furthermore, Mayan customs include a heavy reliance on traditional medicine, folk healers, and midwives who rarely provide pre- and post-natal care.[7] Rather than attempting to supplant centuries-old traditions, however, the doctors learn at least key phrases in the local language, and work alongside traditional healers to ensure integrated, culturally-appropriate careanother tenet of the CHP.

Developed and honed in Guatemala and Honduras-the other country most severely affected by Mitch-CHP cooperation, including the makeup and distribution of the teams, is based on bilateral negotiations. In each case, the Cuban side commits to providing medical professionals who volunteer for a period of at least two years and who do not charge for their services. They are expected to work within the public health system, promoting an intersectoral approach emphasizing collaboration with local civil society and institutions (e.g., churches, non-governmental organizations, community groups, etc.), while not becoming involved in local politics. Such long-term service gives doctors time to develop a bond with local residents and to gain deeper knowledge of the local health picture and, in turn, gives the community time to gain confidence in the physicians.

After initial Hurricane Mitch recovery efforts, the Guatemalan and Cuban governments agreed to a massive scaling-up of the program. Today, there are 270 Cuban doctors providing health services in 17 of Guatemala's 22 departments, the majority specialists in family medicine (Table 1). Fiscal responsibility is shared: volunteers receive a modest monthly stipend (up to \$250) for food, housing, and supplies, paid for by Guatemala, while Cuba provides computers with internet access, transportation, and other necessities. Most Cuban doctors are dispatched to rural, largely Maya, underserved areas. According to the United $\mathrm{Na}-$ tions Development Report, the Maya are the least healthy of all Guatemalans, ranking with Botswana and Cameroon on the UN's human development index, far behind their ladino (non-Mayan) compatriots who are nearly on par with Indonesians.[8]

Guatemala also participates in Operación Milagro, a Cuban program offering free eye surgeries for cataracts, glaucoma, eyelid ptosis, pterigium, and other correctable conditions affecting vision. Since it was launched in July 2004 , over 1.5 million people from 34 countries have had their sight restored or improved under this program.[9] Originally, patients were screened by Cuban doctors in their home country and then flown with a family member to Cuba for operations and follow-up; all transportation, food, accommodation, and medical costs were assumed by Cuba.[10] Demand for

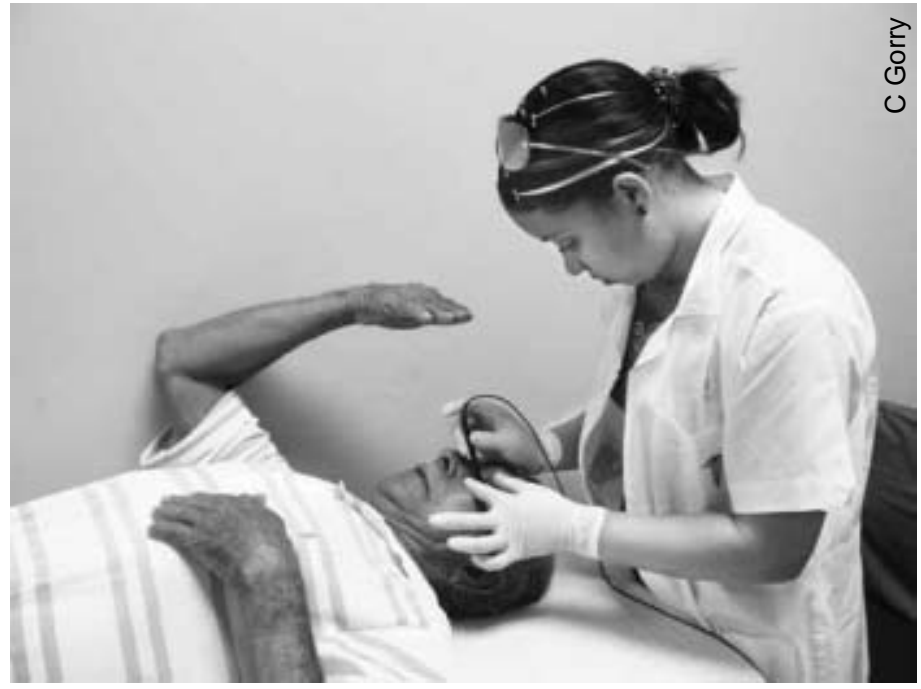

Cuban optometrist Carmen María Pedrosa examines a Guatemalan patient at Escuintla General Hospital as part of Operación Milagro.

the restorative surgeries grew so fast, however, the decision was made to establish in-country ophthalmologic centers, staffed with Cuban specialists and equipped with the latest technology.

The first Guatemalan patients arrived in Cuba in October 2005. To date, 1,704 Guatemalans have undergone sight-improving surgery in Cuba and 21,000 more in Guatemala.[2] As in the program's first stage, all costs, including exams, surgery, corrective lenses, and medicine, are assumed by the Cuba government.

Table 1: Cuban Medical Cooperation in Guatemala, 2008

\begin{tabular}{|l|r|}
\hline Comprehensive Health Program (CHP) & 297 \\
\hline Total participants & $252(85 \%)$ \\
\hline Medical professionals & \\
\hline Medical specialties & 165 \\
\hline Family Medicine & 10 \\
\hline Pediatrics & 17 \\
\hline OB-GYN & 8 \\
\hline Surgery & 12 \\
\hline Internal Medicine & 15 \\
\hline Epidemiology & 2 \\
\hline Microbiology & 4 \\
\hline Anesthesiology & 1 \\
\hline Clinical Laboratory (Technicians) & 2 \\
\hline Dentistry & 11 \\
\hline Medical Residencies & 5 \\
\hline Others & 87 \\
\hline Vision Restoration Program (Operación Milagro) & \\
\hline
\end{tabular}

Total participants

Medical professionals

$18(21 \%)$

Combined Programs

Population served

$2,199,146$

Doctor/patient ratio in areas served by Cuban specialists

$1 \times 8145$

\begin{tabular}{|l|r} 
No. of medical consultations (1998-2008) & $25,004,914$
\end{tabular}

No. of surgeries (1998-2008)

40,677

No. of births attended (1999-2008)

74,237

Source: Cuban Medical Team, Guatemala 2008, PowerPoint presentation. 
By focusing on prevention, health promotion, and communitybased primary care, the program has contributed to overall population health improvement in the country as a whole: according to the United Nations' Human Development Report, life expectancy in Guatemala rose from 64.4 years in 1998[11] to 69.7 years in 2005 (the most recent data available).[8] The same progress can be seen in 1-year olds fully immunized against tuberculosis and measles, percentage of low birthweight babies, as well as infant, under-5, and maternal mortality rates (Table 2). Overall, Guatemala's rank in the Human Development Index rose from 120 in 1998,[11] when the Cuban medical teams arrived, to 118 in 2005.[8]

Table 2: Health Indicators, Guatemala, 1998 and 2005

\begin{tabular}{|l|r|r|}
\hline Indicator & 1998 & \multicolumn{1}{|c|}{2005} \\
\hline Life expectancy & 64.4 & 69.7 \\
\hline Infant mortality (per 1,000 live births) & 41 & 32 \\
\hline Under-5 mortality (per 1,000 live births) & 52 & 43 \\
\hline Maternal mortality (per 100,000 live births; reported) & 190 & 150 \\
\hline Infants with low birthweight & $15 \%$ & $12 \%$ \\
\hline One-year olds fully immunized against tuberculosis & $88 \%$ & $96 \%$ \\
\hline One-year olds fully immunized against measles & $81 \%$ & $77 \%$ \\
\hline
\end{tabular}

Source: United Nations Development Programme Human Development Report 2000, 2007/2008.

The data is even more dramatic when broken down for the underserved areas where the Cuban doctors work, now joined by Guatemalan interns and graduates in some communities. Before their arrival, the infant mortality rate was 40.2 per 1,000 live births in these communities; by 2008 the rate had dropped to 8.9. Maternal mortality had likewise improved, from 491 per 100,000 live births in 1998 to 113.8 by 2008 in the same regions.[2] Organizers of the Cuban teams attribute at least part of the success in improving maternal and child health to joint efforts with community leaders and midwives. Such an integrated approach has emphasized the importance of pre- and post-natal care, trained midwives to be alert to warning signs of complications, and developed collaborative relationships with traditional healers, leading to more effective patient education and case management. In 2007, 90\% of newborns were seen by Cuban doctors in the areas where they worked.[2] Outcomes have also been positively affected by the recently-launched maternal-child health project that coordinates work between the Guatemalan Ministry of Public Health, Cuban doctors, and returning Guatemalan ELAM graduates. Repairs and maintenance of medical equipment by Cuban biomedical engineers have also played a part; from 1999 through December 2008, Cuban volunteers repaired 9,004 pieces of equipment and serviced another 12,785, saving the Guatemalan public health system US $\$ 2.8$ million.[2]

\section{ELAM: Working Towards Sustainability}

The second innovation spurred by the 1998 post-hurricane experience was the founding of the Latin American Medical School (ELAM) with an initial 1,929 students from 18 countries.[12,13] Again, the idea was simple: contribute to ameliorating the crisis in human resources for health, particularly in the Global South, by offering full scholarships to low-income students from the developing world. In return, candidates-recruited from underserved areas-would commit to serving in their home communities upon graduation.[14] Gradually, these new doctors would replace the
Cuban doctors serving in the CHP. "The ideal is for Guatemalan doctors to serve their own people. Ultimately, we can't substitute for them. The goal of the ELAM is for Guatemalans to serve Guatemalans so we can return to Cuba to be there for our people," $\mathrm{Dr}$ Abel Barrios, Deputy Coordinator of the Vision Restoration Program (Operación Milagro) in Guatemala, told MEDICC Review.

But the simple idea behind ELAM belied a complex insertion process for returning graduates, which became glaringly apparent when the first class-over $10 \%$ of which was Guatemalan-graduated in 2005.[15] Fundamental to the ELAM program is inserting graduates into the public health systems of their home countries, a process fraught with obstacles that have included failure in some countries to recognize the ELAM degree, lack of systems for contracting and paying the new doctors, and protests by national medical associations.[16] The first two cohorts of Guatemalan graduates confronted all of these challenges.

"Rejection of the first ELAM graduates caused great anguish," said Dr Jesus Oliva, Dean of the University of San Carlos Medical School in Guatemala, "so we began a dialogue to see how we could facilitate their entry into the Guatemalan health system." This dialogue-between the Guatemalan government and Ministry of Health, the University of San Carlos, (USAC, also the country's medical degree-conferring institution), ELAM deans, and other Cuban medical educators-led to a series of innovative solutions that could serve as a case study in multi-disciplinary, cross-cultural problem solving.

The first major hurdle was the curriculum. Although the ELAM curriculum is accredited by the World Health Organization and the degree recognized in dozens of countries, including the United States,[17] Argentina, and the Dominican Republic, the Cuban context in which the new doctors studied is different from Guatemala's. Malaria, river blindness (oncocercosis), and Chagas' disease, for instance, are not present in Cuba; gunshot wounds and poisonous snake bites are similarly not major health problems there, while drug addiction and domestic violence-relatively rare in Cuba-occur frequently in Guatemala. These gaps in the students' clinical training led to context-specific modifications in the program and some new approaches. For example, Guatemalan ELAM students founded the student organization Eterna Primavera ('Eternal Spring,' the country's nickname), which sets up field work for students during their summer break. Coordinated with the University of San Carlos, teams of Guatemalan students are paired with and supervised by Cuban doctors practicing throughout the country, giving students the opportunity to see and treat conditions they will frequently find in their own practice.

Formally integrating ELAM graduates into the national public health system was the next step. This challenge turned into an opportunity for contextually-appropriate supplemental training and further innovation. In 2007, national health authorities decided to involve new ELAM graduates in a new program aimed at reducing maternal and infant mortality. Working for three months alongside Cuban physicians provides them more hands-on experience before beginning their one-year mandatory social service. Upon completion of social service-involving additional rotations in specialties such as pediatrics, internal medicine, obstetrics and gynecology - the graduates' ELAM degree is recognized as equivalent to a degree from USAC. As a result, 331 Guatemalan ELAM graduates currently work in the country's public health 
system.[18] A newer model under development dovetails fifthyear ELAM and USAC curriculum content so students graduate with a dual ELAM-USAC degree.

\section{The Road Ahead}

In February 2009, a new initiative was launched allowing ELAM graduates to pursue residencies in Guatemala under the tutelage of Cuban medical educators, another element aimed at enhancing the program's sustainability. Patients such as those from the 13 municipalities served by the Escuintla General Hospital are receiving tangible benefits from this residency program plus hospital infrastructure improvements, as reported in Prensa Libre, one of Guatemala's widest circulating dailies. The hospital saw a $38 \%$ increase in patients served between 2007 and 2008. Maternity and pediatrics services extended their daily hours from 8 to 24 at this hospital that sees over 200 births a month, 60 by cesarean section.[19]

Yet, from ELAM student selection to graduate tracking, Cuban medical educators note that there is still much to be learned to maximize the population health impact of these new physicians. "We're focused on quality, not quantity," head of Cuban medical collaboration in Guatemala Dr José Ramón Ruiz told MEDICC Review. "We've refined the student selection process to prioritize qualified students from remote communities, with a strong commitment to return to those communities." Time will tell if this strategy brings results, and a global ELAM Observatory has been set up to track the graduates' and the program's effectiveness in improving health outcomes. The massive database project follows students from entry into the medical school to their insertion in health systems around the world. In Guatemala, the Observatory is updated monthly and its analysis will provide a fundamental evidence base for further innovation by Guatemalan and Cuban health authorities as they move into the second decade of bilateral cooperation. -1 -

\section{References \& Notes}

1. Inter-American Development Bank. Central America after Hurricane Mitch [monograph on the Internet]. 2000 May; [cited 2009 Apr 14]. Available from: www.iadb.org/regions/re2/consultative_group/backgrounder5.htm.
2. Brigada Médica Cubana Guatemala 2008 [PowerPoint presentation]. 2009 Jan.

3. Alonso O. Colaboración Médica Cubana: Guatemala, Del Tocororo al Quetzal. Havana:Editorial Pablo de la Torriente. 2001. p. 30.

4. For more details on these programs, see Cuban Health Cooperation Turns 45. MEDICC Review. 2008 Summer;10(3):44-7.

5. Ubieta E. La Utopía rearmada: Historias de un viaje al nuevo mundo. Havana: Casa Editora Abril. 2002. p. 247.

6. Macmillan International Work Group for Indigenous Affairs. 2006. The indigenous world 2006 [monograph on the Internet]; [cited $2009 \mathrm{Apr}$ 14 ]. Available from: www.iwgia.org/graphics/Synkron-Library/Documents/ publications/Downloadpublications/IndigenousWorld/IW\%202006/ IW2006(573pages).pdf

7. In an interview with the author, Cuban surgeon posted at Escuintla General Hospital Dr Marcos Armada stated: "Midwives usually come to us when complications arise during childbirth-uterine ruptures, sepsis and breech births. This is why we underscore the importance of maternal and child health, and work with the community."

8. United Nations Development Programme. Human Development Report 2006. Más allá de la escazez: Poder, pobreza, y la crisis mundial del agua. New York; 2006. p. 272-3.

9. Rio M. South-South Partnerships: Cuba's Vision Restoration Program [PowerPoint presentation]. 2009 Apr.

10. For more on Cuba's vision restoration program, see Gorry, C. Sight for sore eyes. MEDICC Review. 2008 Spring. 10(2):49-51.

11. United Nations Development Programme. Human Development Report 2000. New York; 2000. p.159.

12. Editorial de Prensa Latina. Entrevista con el Doctor Juan Domingo Carrizo, Rector de la Escuela Latinoamericana de Medicina. Primera Graduación Escuela Latinoamericano de Medicina. Revista Panorama Cuba y Salud: Edición Especial por la primera graduación. Prensa Latina, Havana. 2005

13. There are currently over 8,000 students from 30 countries studying at the ELAM.

14. In the four graduating classes between 2005 and 2008, 6,047 new doctors received their medical degrees from ELAM.

15. Of the 1,498 graduates in 2005,187 were Guatemalan, the second-largest group after Hondurans, which graduated 215. MEDICC Review. 2005 AugSept; $7(8): 3$

16. For example, see Forero J. Venezuela: Protest against Cuban doctors. The New York Times. 2005 July 16; World Briefing; BBC. Bolivia protest over Cuba medics. BBC News. 2006 Jun 22; and BBC News. Venezuela medics march over jobs. 2005 July 17.

17. Like all medical graduates who aspire to practice in the USA, ELAM graduates from the United States are required to pass the US Medical Licensing Exam (USMLE).

18. Author interview with Cuban medical cooperation chief in Guatemala, Jose Ramon Ruiz, February 4, 2009.

19. Paredes E. Atienden a pacientes de 13 municipios. Prensa Libre. 2009 Feb 2;46.

\section{Erratum}

Llibre J, Fernández Y, Marcheco B, Contreras N, López AM, Otero M, Gil I, Guerra M, García M, Bayarre H. Prevalence of Dementia and Alzheimer's Disease in a Havana Municipality: A Community-Based Study among Elderly Residents. MEDICC Review. 2009;11(2):29-35.

Page 29, Abstract, Introduction, final sentence should read: "Its population of 11.2 million is aging rapidly: by the year 2020 it is estimated that personas aged $\geq 60$ years will comprise $21.6 \%$ of the population, making Cuban society the "oldest" in Latin America."

Page 29, Introduction, paragraph 4 should read: "Cuba is a developing country with health indicators similar to those of developed countries and a rapidly aging population of 11.2 million. By the year 2020 Cuba will have the oldest population in Latin America, with adults aged $\geq 60$ years accounting for $21.6 \%$ of total population." 